\title{
Autosomal dominant cerebellar ataxia
}

INSERM

\section{Source}

INSERM. (1999). Orphanet: an online rare disease and orphan drug data base. Autosomal dominant cerebellar ataxia. ORPHA:99

Autosomal dominant cerebellar ataxia (ADCA) describes a clinically and genetically heterogeneous group of neurodeg enerative diseases characterized by a slowly progressive ataxia of gait, stance and limbs, dysarthria and/or oculomotor disorder, due to cerebellar degeneration in the absence of coexisting diseases. The degenerative process can be limited to the cerebellum (ADCA type 3 ) or may additionally involve the retina (ADCA type 2), optic nerve, ponto-medullary systems, basal ganglia, cerebral cortex, spinal tracts or peripheral nerves (ADCA type 1). In ACDA type 4, a cerebellar syndrome is associated with epilepsy. 